\title{
Iron absorption in normal and d, 1-ethionine-treated rats before and after the administration of pancreatin ${ }^{1}$
}

\author{
B. BROZOVIĆ, O. POPOVIĆ, D. OBRADOVIĆ, AND SMILJA PENDIĆ \\ From the Institutes of Pathological Physiology, Pathology, Radiology, Medical Faculty and Department \\ of Medicine, City Hospital, Belgrade
}

EDITORIAL COMMENT The markedly increased absorption of iron as measured in rats by whole body counting when the pancreas was destroyed by d,l-ethionine is reduced to normal limits when pancreatin is mixed with the test dose of iron. Pancreatin when given to normal rats also slightly reduces iron absorption.

It is well known that pancreatic damage either induced in experimental animals (Taylor, Stiven, and Reid, 1931, 1935; Kinney, Finch, Kaufman, Hegsted, and Partington, 1950; Kinney, Kaufman, and Klavins, 1955) or acquired in the course of chronic pancreatic disease (Andersen, 1938) increases iron accumulation in tissues, particularly in the liver. Increased iron absorption was assumed to occur in these conditions and recently this has been demonstrated directly in man and animals by radioactive iron absorption tests (Davis and Badenoch, 1962; Libre, Kennedy, and McFarland, 1964).

A decrease in iron absorption, on the other hand, is caused by the stimulation of pancreatic secretion with pancreozymin and secretin in rats (Bothwell, 1964). Furthermore, children with cystic fibrosis treated with pancreatin absorb iron poorly and may develop a mild iron-deficiency anaemia (Smith, 1964), and the addition of normal duodenal juice (Linscheer, Greenberg, Moore, and Chalmers, 1964) or pancreatin (Malpas and Callender, 1964) to the test dose of iron reduced iron absorption in a group of cirrhotic patients. The same results were reported in patients with haemochromatosis (Davis and Biggs, 1964a) and similar results have been obtained in the isolated loop of the small intestine (Davis and Biggs, 1964b).

These findings would suggest that the pancreatic secretion contains a factor whose absence or presence may influence the absorption of iron. The purpose of this study was to observe in detail the effect of pancreatin on the rate of iron absorption in normal rats

\footnotetext{
${ }^{1}$ The work was supported by a Medical Fac slty research grant from the University of Belgrade.
}

and rats whose exocrine pancreas has been damaged by d,l-ethionine. At the same time, detailed histological studies were carried out to assess the rate of damage produced in the liver and its possible relation to iron absorption.

\section{MATERIALS AND METHODS}

Experiments were carried out on white laboratory rats of both sexes, weighing from 80 to $150 \mathrm{~g}$., fed by standard food for rats and mice and as much water as desired.

The absorption of iron was measured by whole body counting. After food had been withdrawn for 16 hours rats were given 1 to $2 \mu \mathrm{c}$. of ${ }^{59} \mathrm{Fe}$ with the carrier iron in the form of ferrous sulphate, $2.5 \mathrm{mg}$. $/ \mathrm{kg}$. body weight, and ascorbic acid, $10 \mathrm{mg}$./mg. of iron in a solution of approximately $0.5 \mathrm{ml}$. The mixture was administered by siliconized syringe and plastic gastric tube. The whole body radioactivity of rats, placed in the cardboard box, was measured immediately after the administration of radioactive iron by scintillation counter with a 2 inch $\mathrm{NaI}$ crystal with appropriate shielding. As was shown in the previous investigation of day-to-day measurements of iron retention, the fall of activity after the fourth day was very small, and therefore, radioactivity on the fourth day was taken to represent the absorption (Brozović, Pendić, and Nestorović, 1964). In a number of rats the iron absorption test was repeated after eight days and the necessary correction made for retained ${ }^{59} \mathrm{Fe}$ from the previous test.

Destruction of exocrine pancreas was achieved by giving d,1-ethionine subcutaneously twice daily for 10 days (House, Jacobs, and Pansky, 1963), the dose being $1 \mathrm{mg} . / \mathrm{g}$. body weight per day.

When the action of pancreatic extract was investigated, pancreatin (Galenika) was used, $0 \cdot 1 \mathrm{mg}$./g. body weight, mixed with the test dose of radioactive iron.

To estimate the degree of change caused by d,1-ethio- 
nine and the possible accumulation of iron, tissue sections from the pancreas, liver, and spleen were taken from representative groups of control rats and all d,l-ethioninetreated rats. Sections were stained with haematoxylin and eosin. Perls's method was used for demonstration of stainable iron.

The percentage of reticulocytes in control and d,1ethionine-treated rats was followed during the experiment, in order to detect any change in red cell production. Peripheral blood smears were stained with brilliant cresyl-blue and not less than 1,000 red cells were counted in each smear.

\section{RESULTS}

IRON ABSORPTION The absorption results in control and d,l-ethionine-treated rats are illustrated in Figure 1. In control rats the mean iron absorption was $8.3 \%$ (range 1.0 to $15.6 \%$ ). When the pancreatin was added to the test solution iron absorption fell; the mean was $6.1 \%$ (range of 3.6 to $8.0 \%$ ). This difference was significant $(p<0.05)$.

There was a marked and significant $(p<0.001)$ increase of iron absorption in the rats which were treated with d,l-ethionine, the mean value being $16.2 \%$ (range from 12.6 to $24.5 \%$ ). On the other hand, when pancreatin was added to the test solution eight days later, iron absorption fell to $8.7 \%$

IRON ABSORPTION

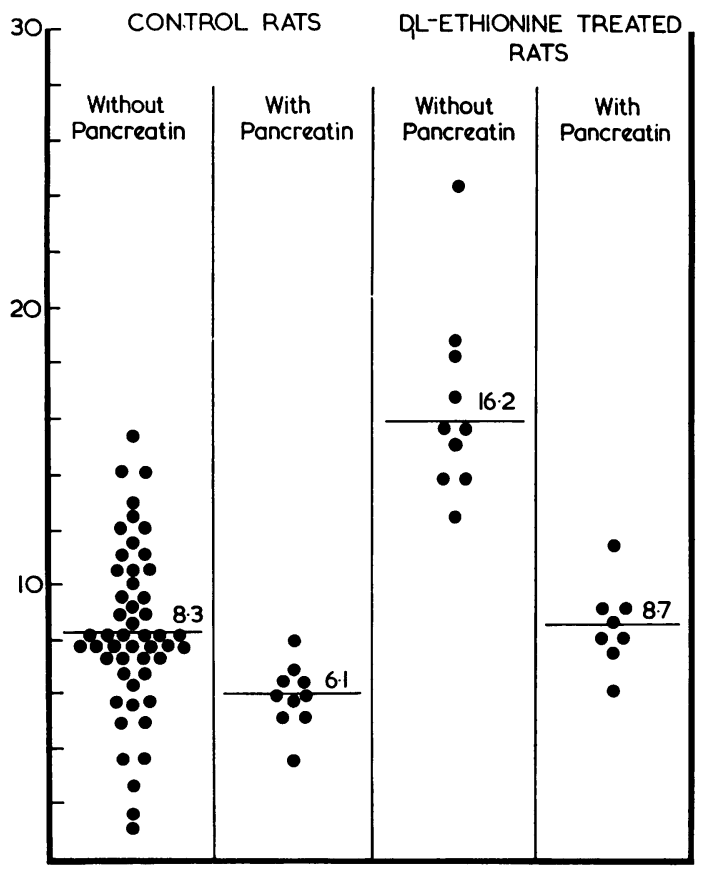

FIG. 1. Iron absorption (per cent) in the control and $d$,l-ethionine-treated rats with and without the addition of pancreatin to the test dose of radioactive iron.
(6.3 to $11.7 \%$ ). Iron absorption in every animal decreased.

The percentage of reticulocytes in rats treated with d,l-ethionine was all the time within normal limits.

HISTOLOGICAL FINDINGS IN D,L-ETHIONINE-TREATED RATS Histological examination of the pancreas in all animals showed lesions with various stages of degeneration and necrosis. Thus, some cells showed vacuolization around the nuclei and the flattened basophilic part of their cytoplasm, while other cells, which had lost their nuclei, were separated from each other and broken down into granular debris. In sharp contrast to the damaged exocrine pancreas were the intact islands of Langerhans (Figs. 2a and 2b). Histological findings in liver sections of different animals varied from animal to animal. In some rats the liver showed no recognizable histological alteration. In others, there were lesions which varied from cloudy swelling and mild fatty changes on the peripheral part of hepatic lobuli to diffuse fatty degeneration with much necrosis (Fig. 3). Only some of the d, l-ethionine-treated rats had stainable iron in liver sections. Examination of spleen sections revealed no difference either in histological structure or in iron content between normal and d, l-ethioninetreated rats.

\section{DISCUSSION}

As was shown earlier, the experimentally induced damage or chronic disease of the pancreas is followed by an increase of iron absorption. This is caused neither by change in erythropoiesis nor in body iron stores. Our iron absorption results and histological findings are in full agreement with those of previous reports (Goldberg, Chaikoff, and Dodge, 1950; Goldberg and Chaikoff, 1951; Koch-Weser and Popper, 1952; Popper, de la Huerga, and KochWeser, 1952; Wachstein and Meisel, 1953; Alvizouri and Warren, 1954; Kinney et al., 1955; Libre et al., 1964).

Pancreatin given to normal rats reduced iron absorption, and Bothwell (1964) observed that the iron absorption in normal rats was reduced by half after administration of pancreatin. The difference we obtained in iron absorption between control rats and the rats which received pancreatin is not so striking, although significant $(\mathrm{p}<0.05)$. It is possible that the method we used for testing iron absorption was not sensitive enough to demonstrate such a small decrease. However, a clear-cut difference was demonstrated in the d,l-ethionine-treated rats given pancreatin; iron absorption fell by half in every animal tested and all had iron absorption within the limits of the normal range. 


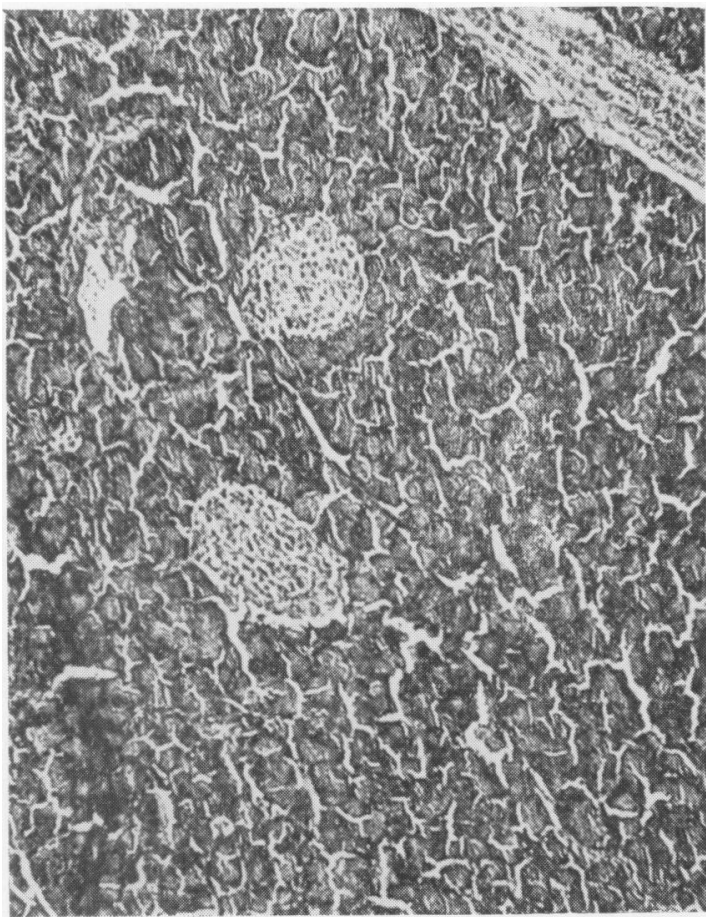

FIG. $2 a$

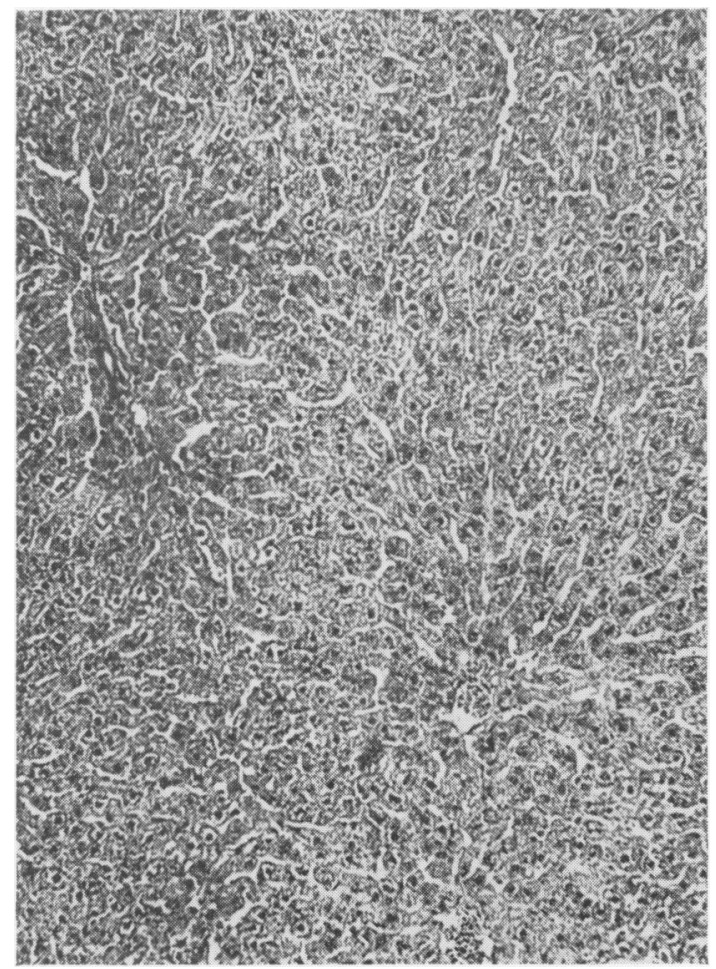

FIG. 3

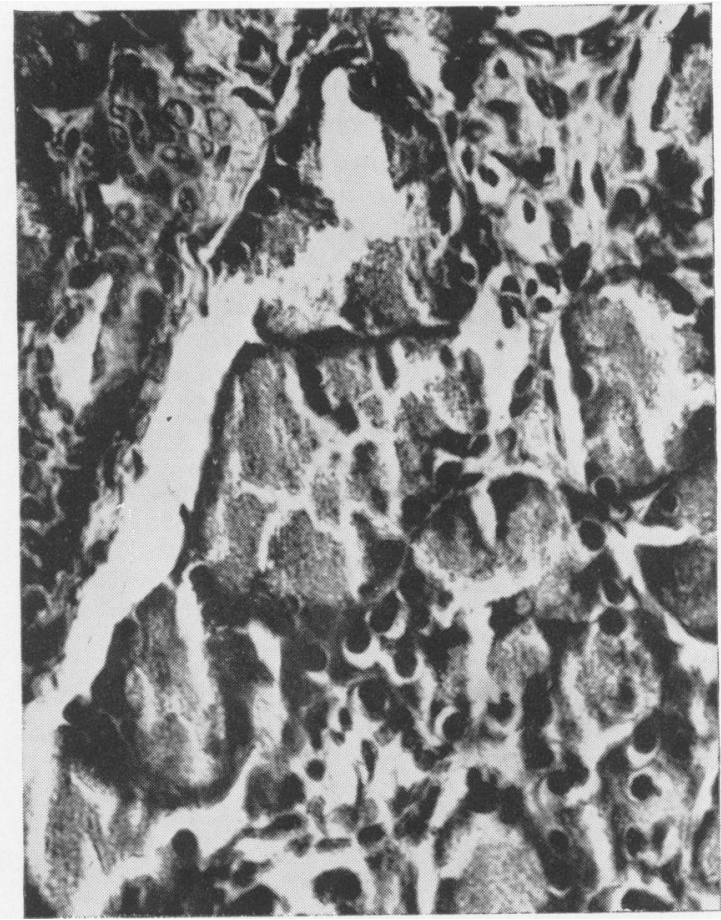

FIG. $2 b$

FIG. 2. The damaged pancreatic tissue in a rat after $d$, l-ethionine treatment. (a) Low-power magnification: the islands of Langerhans are apparently normal. (b) Highpower magnification: degeneration and necrosis of pancreatic acinar cells, slight fibroblastic and lymphocytic infiltration (stained with haematoxylin and eosin).

FIG. 3. Cloudy swelling and moderate fatty degeneration of hepatic cells is seen in the liver of a rat treated by d,l-ethionine. Low-power magnification (stained with haematoxylin and eosin). 
Recently, the increase of iron absorption was also demonstrated in chronic liver disease (Malpas and Callender, 1964; Greenberg, Strohmeyer, Hine, Keene, Curtis, and Chalmers, 1964; Linscheer et al., 1964). This was supposed to be due to the pancreatic lesion but liver damage might also have affected it. In our experiments we failed to find any relation between iron absorption and the grade of damage produced in liver by d,l-ethionine. Moreover, some of the rats had no liver damage at all.

The mechanism of the action of pancreatin is not quite clear. The change in iron absorption following physiological stimulation is slow, and, for example, after acute haemorrhage, the maximal absorption is reached after three to five days (Weintraub, Conrad, and Crosby, 1964; Brozović et al., 1964), but the presence of pancreatin changes absorption instantaneously. This would suggest that there is a factor or factors in pancreatin itself capable of inhibiting the uptake of iron by intestinal cells, most probably by changing the internal milieu of the intestine than by changing intestinal cells.

\section{SUMMARY}

The rate of iron absorption in control rats and rats whose pancreas was damaged by d,l-ethionine was investigated before and after the administration of pancreatin. Pancreatin slightly reduced iron absorption in normal rats; the increased iron absorption was reduced markedly to within normal limits in d,l-ethionine-treated rats, all of which showed severe damage to the pancreas. There was no relation between the rate of iron absorption and liver damage caused by d,l-ethionine.

The authors would like to thank Dr. D. L. Mollin, Department of Haematology, Postgraduate Medical School of London, for his valuable advice and help in the preparation of this manuscript.

\section{REFERENCES}

Andersen, D. H. (1938). Cystic fibrosis of the pancreas and its relation to celiac disease. Amer. J. Dis. Child., 56, 344-399.
Alvizouri, M., and Warren, S. (1954). Effects of DL-ethionine on the pancreas and other organs. Arch. Path., 57, 130-137.

Bothwell, T. H. (1964). In Discussion: S. T. Callender, Digestive absorption of iron. In Iron Metabolism: An International Symposium sponsored by CIBA, Aix-en-Provence, 1963, edited by F. Gross, p. 99. Springer, Berlin.

Brozović, B., Pendić, S., and Nestorović, N. (1964). The investigation of iron absorption in rats by radioactive iron. Reported at the $V$ th Congress of Radiology and nuclear Medicine, 24-26 September, Belgrade.

Davis, A. E., and Badenoch, J. (1962). Iron absorption in pancreatic disease. Lancet, 2, 6-8.

-, and Biggs, J. C. (1964a). Iron absorption in haemochromatosis and cirrhosis of the liver. Aust. Ann. Med., 13, 201-203.

,--1 (1964b). Iron absorption and the pancreas. In Abstracts Xth Congress of the International Society for Haematology, Stockholm. Munksgaard, Copenhagen.

Goldberg, R. C., and Chaikoff, I. L. (1951). Selective pancreatic acinar destruction by DL-ethionine. Arch. Path., 52, 230-238.

,-- and Dodge, A. H. (1950). Destruction of pancreatic acinar tissue by DL-ethionine. Proc. Soc. exp. Biol. (N.Y.), 74, 869872.

Greenberg, M. S., Strohmeyer, G., Hine, G. J., Keene, W. R., Curtis, G., and Chalmers, T. C. (1964). Studies in iron absorption. III. Body radioactivity measurements of patients with liver disease. Gastroenterology, 46, 651-661.

House, E. L., Jacobs, M. S., and Pansky, B. (1963). The effect of D-L-ethionine on the pancreas of normal and pregnant hamsters. Anat. Rec., 145, 89-93.

Kinney, T. D., Finch, C. A., Kaufman, N., Hegsted, M., and Partington, P. F. (1950). The relationship of the pancreas to the absorption of iron. Amer. J. Path., 26, 746.

- Kaufman, N., and Klavins, J. (1955). Effect of ethionineinduced pancreatic damage on iron absorption. J. exp. Med. 102, 151-156.

Koch-Weser, D., and Popper, H. (1952). Hepatic fibrosis produced by chronic ethionine feeding. Proc. Soc. exp. Biol. (N.Y.), 79, 34-37.

Libre, E. P., Kennedy, J. N., and McFarland, W. (1964). Mechanism of increased iron absorption associated with pancreatic damage. Abstracts Xth Congress of the International Society for Haematology, Stockholm. Munksgaard, Copenhagen.

Linscheer, W. G., Greenberg, M. S., Moore, E. W., and Chalmers, T. C. (1964). Studies in iron absorption. IV. Absorption in the proximal small intestine in patients with cirrhosis. Gastroenterology, 46, 662-670.

Malpas, J. S., and Callender, S. T. (1964). Iron absorption in liver disease. Sangre, (Barcelona), 9, 246-248.

Popper, H., de la Huerga, J., and Koch-Weser, D. (1952). Hepatic and pancreatic changes produced in rats by ethionine and their relation to human lesions. Amer. J. Path., 28, 518-519.

Smith, R. S. (1964). Iron absorption in cystic fibrosis. Brit. Med. J., 1, 608-609.

Taylor, J., Stiven, D., and Reid, E. W. (1931). Haemochromatosis in a depancreatised cat. J. Path. Bact., 34, 793-797.

$\left.-, \frac{1}{-}, 1935\right)$. Experimental and idiopathic siderosis in cats. Ibid., 41, 397-405.

Wachstein, M., and Meisel, E. (1953). Cellular changes accompanying degenerative and regenerative phase of ethionine-induced pancreatic damage in the rat. Lab. Invest., 2, 253-260.

Weintraub, L. R., Conrad, M. E., and Crosby, W. H. (1964). The significance of iron turnover in the control of iron absorption. Blood, 24, 19-24. 